\title{
Metal-promoted Synthesis of Cyclic Carbonates from 1,2-diols and Carbon Dioxide
}

\author{
Chun-Xiang Guo, Ran Ma and Liang-Nian $\mathrm{He}^{*}$
}

State Key Laboratory and Institute of Elemento-Organic Chemistry, Collaborative Innovation Center of Chemical Science and Engineering (Tianjin), Nankai University, Tianjin, 300071, People's Republic of China

\begin{abstract}
Chemical fixation of $\mathrm{CO}_{2}$ to value-added products/materials/fuel has attracted more and more attention from both academia and governmental agencies all over the worldsince $\mathrm{CO}_{2}$ is an easily available and sustainable $\mathrm{C}_{1}$ resource with the advantage of being abundant, nontoxic, nonflammable and renewable. Synthesis of organic carbonates starting from $\mathrm{CO}_{2}$ is one of the most promising methodologies and has been widely investigated. The use of $\mathrm{CO}_{2}$ and 1,2-diols can bring many advantages, such as reusing the byproducts generated in the industrial dimethyl carbonate (DMC) process and simplifying the post purification process. In this paper, synthetic methods with reaction mechanism of ethylene carbonate (EC), propylene carbonate (PC) and glycerol carbonate from $\mathrm{CO}_{2}$ and ethylene glycol (EG), or propylene glycol (PG) or glycerol are systematically discussed.
\end{abstract}

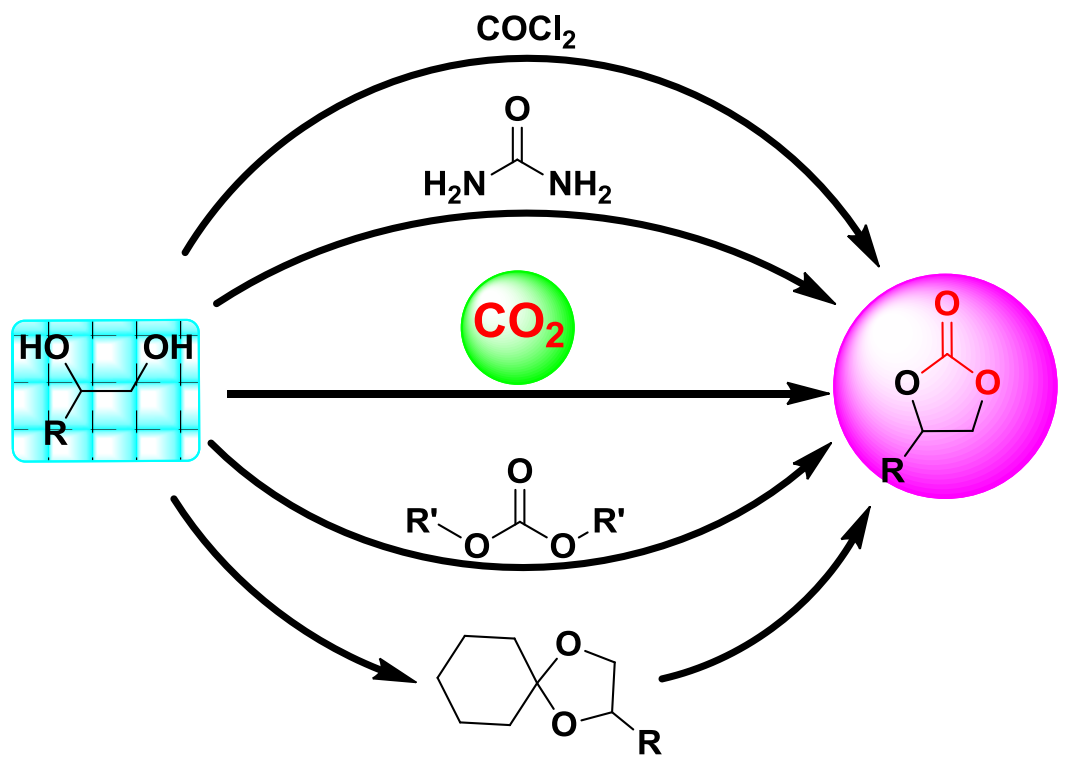

Keywords: Carbon dioxide, catalysis, cyclic carbonate, glycerol, glycol.

\section{INTRODUCTION}

Carbon dioxide as one of the main greenhouse gases has badly endangered the environment in association with global warming, sea-level-rise and species extinction [1]. The concentration of $\mathrm{CO}_{2}$ in the atmosphere has risen up speedily from $280 \mathrm{ppm}$ to $380 \mathrm{ppm}$ in the past 200 years and this trend will be maintained for a long term [2]. On the other side of the coin, $\mathrm{CO}_{2}$ is a safe, cheap and abundant $\mathrm{C}_{1}$

*Address correspondence to this author at the State Key Laboratory and Institute of Elemento-Organic Chemistry, Collaborative Innovation Center of Chemical Science and Engineering (Tianjin), Nankai University, Tianjin, 300071, People's Republic of China; Tel.: (+86) 22-23503878;

Fax: (+86) 22-23503878; E-mail: heln@ nankai.edu.cn building block in organic synthesis with enormous potential applications [3, 4]. Chemical fixation of $\mathrm{CO}_{2}$ into valueadded products has attracted more and more attention from both the scientific communities and governmental agencies. Generous efforts have been devoted to the development of various efficient chemical approaches for the utilization of $\mathrm{CO}_{2}$, in which the production of cyclic carbonate is an effective route [4-6].

Organic carbonates, which have favorable properties with high boiling/flash points, low odor levels, low evaporation rates and low toxicities, have been used in various domains such as solvents, detergents, monomers for polycarbonates and polyurethanes, electrolytes liquid carrier in lithium and lithium-ion batteries, and so on [7,8]. 
Linear carbonates, for example, dimethyl carbonate (DMC) are widely used as raw materials for the production of polycarbonates in chemical industry. The traditional synthetic method commonly uses toxic and corrosive phosgene as a carbonylating reagent (Scheme 1). In view of green chemistry, indirect utilization of $\mathrm{CO}_{2}$ and 1,2-diols to form DMC may avoid facility corrosion and reduce the environmental burden $[9,10]$. DMC synthesis directly from methanol and $\mathrm{CO}_{2}$ is one of the most anticipated routes. Several transition metals have been developed to promote this process, whereas productivity is far from being applied to industrial exploitation due to the thermodynamic limitation [11-13]. One strategy is to go through the transesterification of methanol with cyclic carbonate e.g. PC or EC to afford DMC ,. But some shortcomings still exist: (1) epoxy compounds are expensive and toxic; (2) the coproduct i.e. 1,2-diol is an oversupplied; (3) separation of DMC from 1,2-diol is an energy-extensive process .

If cyclic carbonate ( $\mathrm{PC}$ or $\mathrm{EC}$ ) could be synthesized from the corresponding 1,2-diol and $\mathrm{CO}_{2}$, the process would be more valuable since the 1,2-diol can be recycled, the overall reaction can be regarded as DMC production from $\mathrm{CH}_{3} \mathrm{OH}$ and $\mathrm{CO}_{2}$.
There are two routes to synthesize cyclic carbonates from 1,2-diols and $\mathrm{CO}_{2}$. One is direct dehydration of 1,2diols and $\mathrm{CO}_{2}$ promoted by metallic oxides, metal carbonates, organic bases and transition metal complexes with the aid of physical or chemical dehydrating agent. Another is an indirect method by using derivatives of 1,2diols to overcome the thermodynamic limitation. In this paper, we attempt to feature the advances in the field of cyclic carbonate synthesis from 1,2-diols and $\mathrm{CO}_{2}$ except electrochemical routes.

\section{DIRECT COUPLING OF 1,2-DIOL AND $\mathrm{CO}_{2}$}

\subsection{Metallic Oxide/Acetate-catalyzed Cyclic Carbonate Synthesis}

Tomishige $[14,15]$ and co-workers have reported that the $\mathrm{CeO}_{2}-\mathrm{ZrO}_{2}$ mixed oxide by calcining hydroxides in air can catalyze the synthesis of cyclic carbonate from $\mathrm{CO}_{2}$ and 1,2diol with high activity and selectivity. The catalytic activity depends on the molar ratio of $\mathrm{Ce}$ to $\mathrm{Zr}$ and preparative temperature. The highest activity is reached when $\mathrm{Ce} /(\mathrm{Ce}+\mathrm{Zr})=0.33$ is used and calcined at $1273 \mathrm{~K}$. No carbonate is detected when $\mathrm{ZrO}_{2}$ is used alone, suggesting

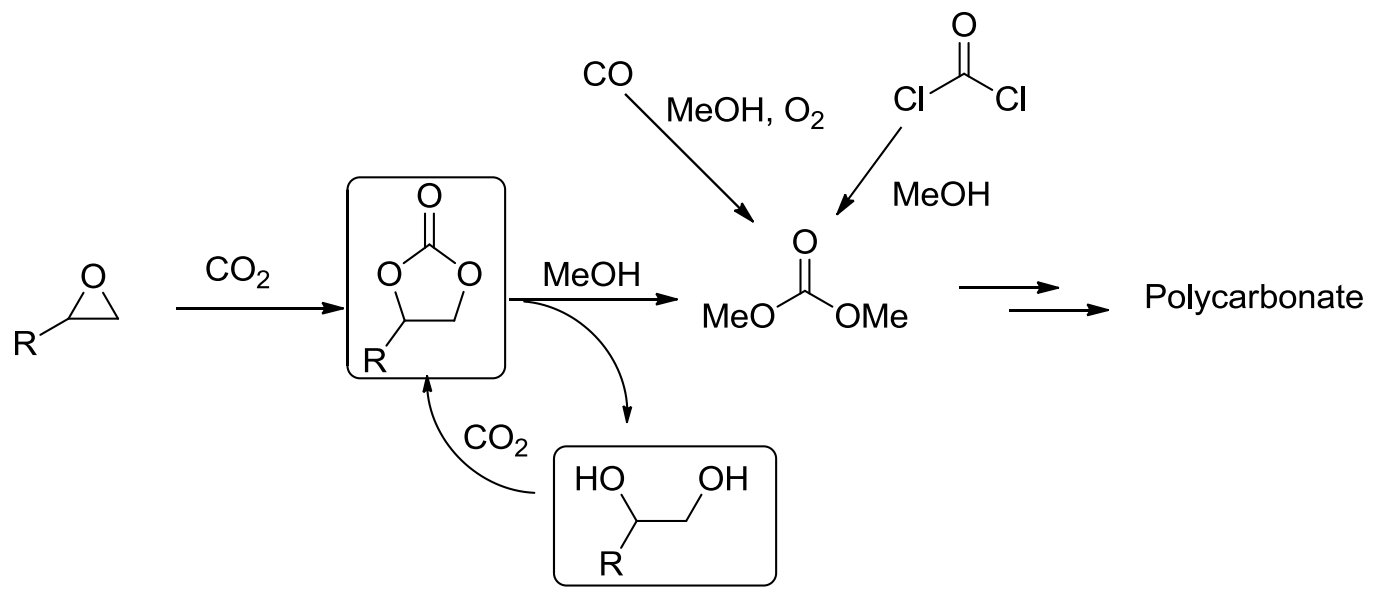

Scheme 1. Synthetic methods for DMC production.

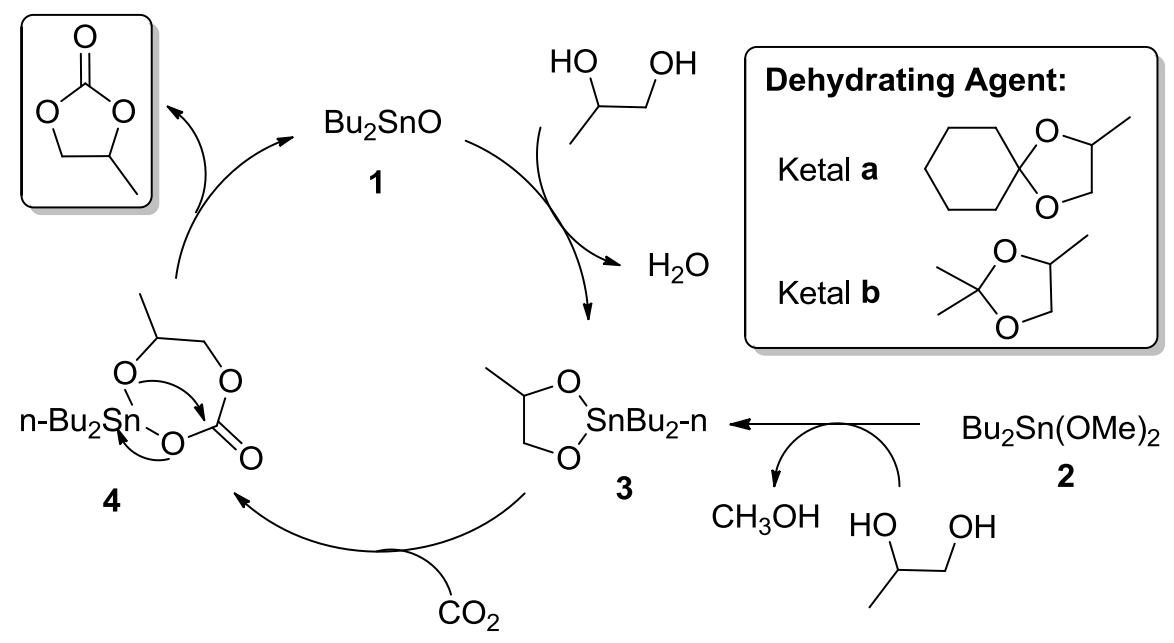

Scheme 2. The proposed reaction mechanism for the $\mathrm{Bu}_{2} \mathrm{SnO}$-catalyzed $\mathrm{PC}$ synthesis from $\mathrm{CO}_{2}$ and $\mathrm{PG}$. 
that $\mathrm{CeO}_{2}$ could be a real active species and the role of $\mathrm{ZrO}_{2}$ is to maintain sufficient surface area.

Sn-complexes e.g. $\mathrm{Bu}_{2} \mathrm{SnO}$ and $\mathrm{Bu}_{2} \mathrm{Sn}(\mathrm{OMe})_{2}$, known as efficient catalysts for DMC preparation from $\mathrm{CH}_{3} \mathrm{OH}$ and $\mathrm{CO}_{2}$ [16-18], have been successfully applied to cyclic carbonate synthesis with $99.9 \%$ selectivity and the highest TON (Turnover number) of 68 [19]. The conversion of PG is notably improved when N,N-dimethylformamide (DMF) is added as co-solvent. But no reaction occurs when DMF alone is used . Less toxic $\mathrm{Ti}(\mathrm{OPr})_{4}$ also exhibits good activity for the reaction of $\mathrm{PG}$ and $\mathrm{CO}_{2}$ to form $\mathrm{PC}$ under similar conditions.

Though the perfect selectivity could be attained under the optimal reaction conditions, the PC yield is unsatisfactory. This is probably because the reaction is controlled by thermodynamic equilibrium. Therefore, it is necessary to remove water in situ generated during the reaction. Furthermorw, when a ketal (cyclohexanone cyclic propylene ketal, ketal a or 2,2,4-trimethyl-1,3-dioxolane, ketal b) is used as a dehydrating agent, the PC yield is greatly enhanced [19].

A plausible mechanism for the $\mathrm{Bu}_{2} \mathrm{SnO}$-catalyzed synthesis of cyclic carbonate from $\mathrm{PG}$ and $\mathrm{CO}_{2}$ has been proposed as illustrated in Scheme 2: At first, $n-\mathrm{Bu}_{2} \mathrm{SnO}$ reacts with $\mathrm{PG}$ to give 2,2-dibutyl-1,3,2-dioxastannolan 3; since $\mathrm{Sn}-\mathrm{O}$ bond is prone to $\mathrm{CO}_{2}$ insertion, the cyclic tin carbonate 4 then is generated from complex 3; finally, intramolecular nucleophilic attack of alkoxy group at the carbonyl carbon atom results in $\mathrm{PC}$ formation with regeneration of dibutyltin oxide. In addition, $\mathrm{Bu}_{2} \mathrm{Sn}(\mathrm{OMe})_{2}$ gave comparable catalytic activity with $\mathrm{Bu}_{2} \mathrm{SnO}$ [20].

The transesterification of EC/PC with glycerol is found to be only one method for glycerol carbonate synthesis until Angela [21] and coworkers have reported glycerol carbonate synthesis directly from glycerol and $\mathrm{CO}_{2}(5 \mathrm{MPa})$ at $450 \mathrm{~K}$ in the presence of the tin-catalyst. In particular, $n$ $\mathrm{Bu}_{2} \mathrm{Sn}\left(\mathrm{OCH}_{3}\right)_{2}$ displays relatively higher activity than $n$ $\mathrm{Bu}_{2} \mathrm{SnO}$, while $\mathrm{Sn}(\mathrm{OMe})_{2}$ reacts with $\mathrm{CO}_{2}$ to afford $[(\mathrm{MeO}) \mathrm{Sn}[\mathrm{OC}(\mathrm{O}) \mathrm{OMe}]]_{\mathrm{n}}$ and thus is inactive for glycerol carbonate synthesis. $n-\mathrm{Bu}_{2} \mathrm{Sn}(\mathrm{OMe})_{2}$ initially reacts with glycerol to afford $n-\mathrm{Bu}_{2} \mathrm{Sn}($ glycerol- $2 \mathrm{H})$, which then could either oligomerize or incorporate with $\mathrm{CO}_{2}$ to generate glycerol carbonate. The oligomer precipitates from the reaction mixture and can not further react with $\mathrm{CO}_{2}$, leading to decrease in the catalytic activity as shown in Scheme $\mathbf{3}$ [22].

In George's report, catalytic amount of $n$ - $\mathrm{Bu}_{2} \mathrm{SnO}$ $(1 \mathrm{~mol} \%)$ is used to prepare glycerol carbonate from glycerol and $\mathrm{CO}_{2}$ in $\mathrm{CH}_{3} \mathrm{OH}$ [23]. $\mathrm{CH}_{3} \mathrm{OH}$ plays vital role in promoting the reaction. $\mathrm{CH}_{3} \mathrm{OH}$ not only works as a solvent, but also facilitates the reaction. At least 25-30 mol\%

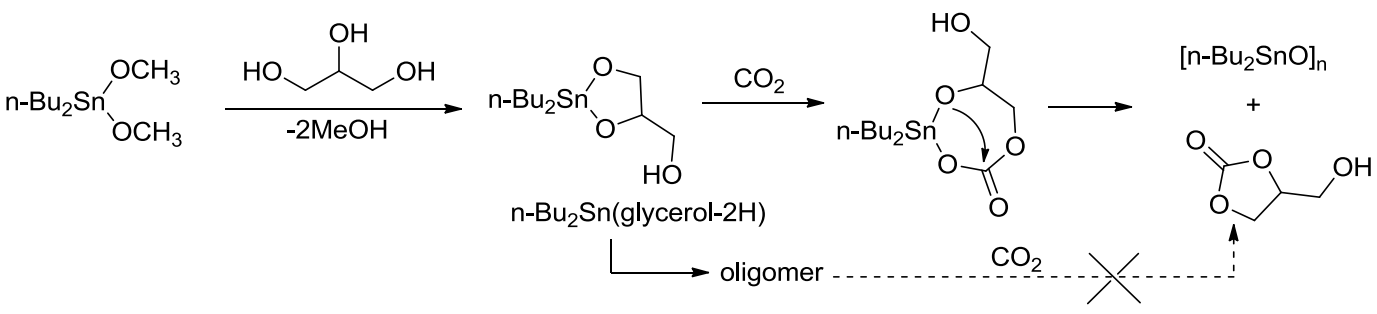

Scheme 3. Synthesis of glycerol carbonate from $\mathrm{CO}_{2}$ and glycerol promoted by $n-\mathrm{Bu}_{2} \mathrm{Sn}(\mathrm{OMe})_{2}$.

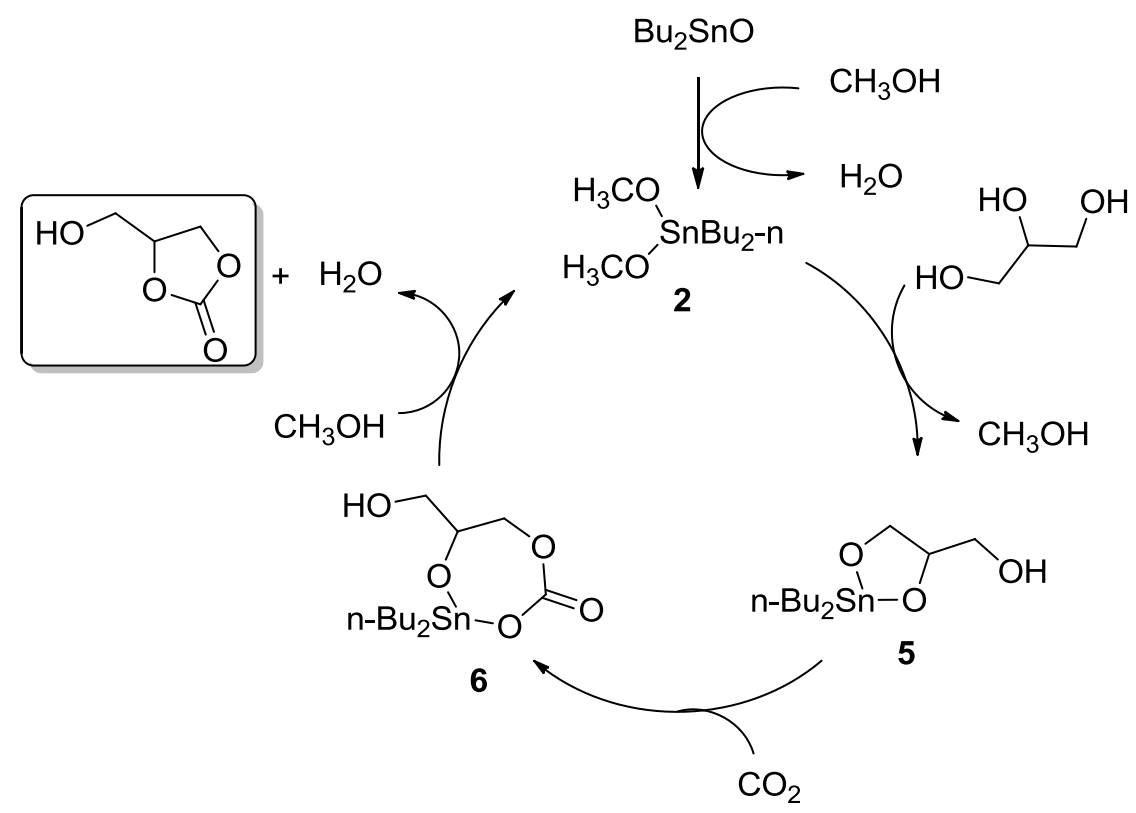

Scheme 4. $\mathrm{Bu}_{2} \mathrm{Sn}(\mathrm{OMe})_{2}$-catalyzed $\mathrm{PC}$ synthesis from $\mathrm{CO}_{2}$ and $\mathrm{PG}$. 
methanol (relative to glycerol) is required for performing the reaction smoothly. Although $n-\mathrm{Bu}_{2} \mathrm{SnO}$ is known as the catalyst for DMC formation, no DMC is detected in this reaction system. The yield of glycerol carbonate can reach as high as $35 \%$ when $13 \mathrm{X}$ (soda) zeolite is introduced as a dehydrating reagent under optimal conditions. The possible mechanism is proposed as shown in Scheme 4: $\mathrm{Bu}_{2} \mathrm{SnO}$ is activated by methanol to give the active species $\mathbf{2}$, which is quite different from previous reports; $\mathbf{2}$ is then converted into 5 with the formation of glycerol carbonate [21].

Low toxic magnesium and its oxide have been developed for the synthesis of PC from PG and $\mathrm{CO}_{2}$ without any solvent or additive [24]. PC is detected as the sole product and a variety of alcohols such as glycol, phenyl glycol, and even $\mathrm{CH}_{3} \mathrm{OH}$ work well. Other metal oxides such as $\mathrm{ZnO}$, $\mathrm{MgO}$ and $\mathrm{Al}_{2} \mathrm{O}_{3}$ are also found to be active and the activity is higher than that of the two-component $\mathrm{CeO}_{2}-\mathrm{ZrO}_{2}$ and the homogeneous tin catalysts.

Potassium salt-modified $\mathrm{ZnO}$ catalyst developed by Sun et al. [25] displays excellent activity for the synthesis of PC. $\mathrm{ZnO}$ modified with $\mathrm{KI}(4 \mathrm{mmol} / \mathrm{g})$ performs the highest activity. However, superfluous KI content leads to a decrease in activity, presumably due to that plethoric KI makes uneven dispersion of $\mathrm{KI}$ on $\mathrm{ZnO}$. The activity can be further improved by calcination [26].

In this system, $\mathrm{CH}_{3} \mathrm{CN}$ is used as not only a solvent but also a dehydrating reagent to remove water as shown in
Scheme 5. The acetamide generated from the reaction of $\mathrm{CH}_{3} \mathrm{CN}$ and $\mathrm{H}_{2} \mathrm{O}$ can further react with $\mathrm{H}_{2} \mathrm{O}$ to form acetic acid, which then undergoes the esterification with $\mathrm{PG}$ to produce propylene glycol-2-acetate. Although the PC yield achieves $12.6 \%$, the selectivity is only $53 \%$. To improve the selectivity, ammonium carbonate $\left[\left(\mathrm{NH}_{4}\right)_{2} \mathrm{CO}_{3}\right]$ is employed [27]. It is well known that $\left(\mathrm{NH}_{4}\right)_{2} \mathrm{CO}_{3}$ can be easily degraded to produce $\mathrm{NH}_{3}$. As a result, the addition of $\mathrm{NH}_{3}$ prevents from further hydrolysis of acetamide and thereby improves PC selectivity up to $100 \%$.

La-Zn mixed oxides have been utilized forthe glycerol carbonate formation from $\mathrm{CO}_{2}$ and glycerol [28]. Three kinds of $\mathrm{La}$ oxide are evaluated. $\mathrm{La}_{2} \mathrm{O}_{2} \mathrm{CO}_{3}$ shows the best performance compared with $\mathrm{La}(\mathrm{OH})_{3}$ and $\mathrm{La}_{2} \mathrm{O}_{3}$. A series of $\mathrm{La}_{2} \mathrm{O}_{2} \mathrm{CO}_{3}-\mathrm{ZnO}$ oxides with various molar ratios are prepared at specific calcining temperature. The catalyst with molar ratio of $\mathrm{La}: \mathrm{Zn}=1: 4$ and calcining at $773 \mathrm{~K}$ displays the highest activity.

The reason why La-doped catalysts enhance the activity can be explained as follows: on one hand, addition of La increases the specific surface area and the exposed basic sites. On the other hand, introduction of $\mathrm{La}_{2} \mathrm{O}_{2} \mathrm{CO}_{3}$ significantly increases the amount of lattice oxygen ( $\mathrm{La}-\mathrm{O}$ pairs) on the surface which leads to an increase in moderately basic sites. In addition, electron transfer from the $\mathrm{Zn}$ to the $\mathrm{La}$ or $\mathrm{O}$ improves the binding energy of $\mathrm{Zn} 2 \mathrm{p}_{3 / 2}$ and makes $\mathrm{La}-\mathrm{Zn}$ catalyst more favorable to interact with glycerol $[29,30]$.

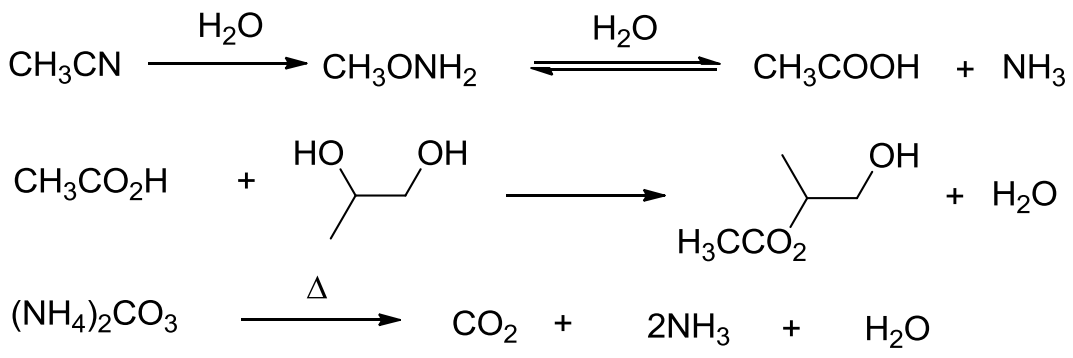

Scheme 5. $\mathrm{CH}_{3} \mathrm{CN}$ with $\left(\mathrm{NH}_{4}\right)_{2} \mathrm{CO}_{3}$-promoted PC formation.

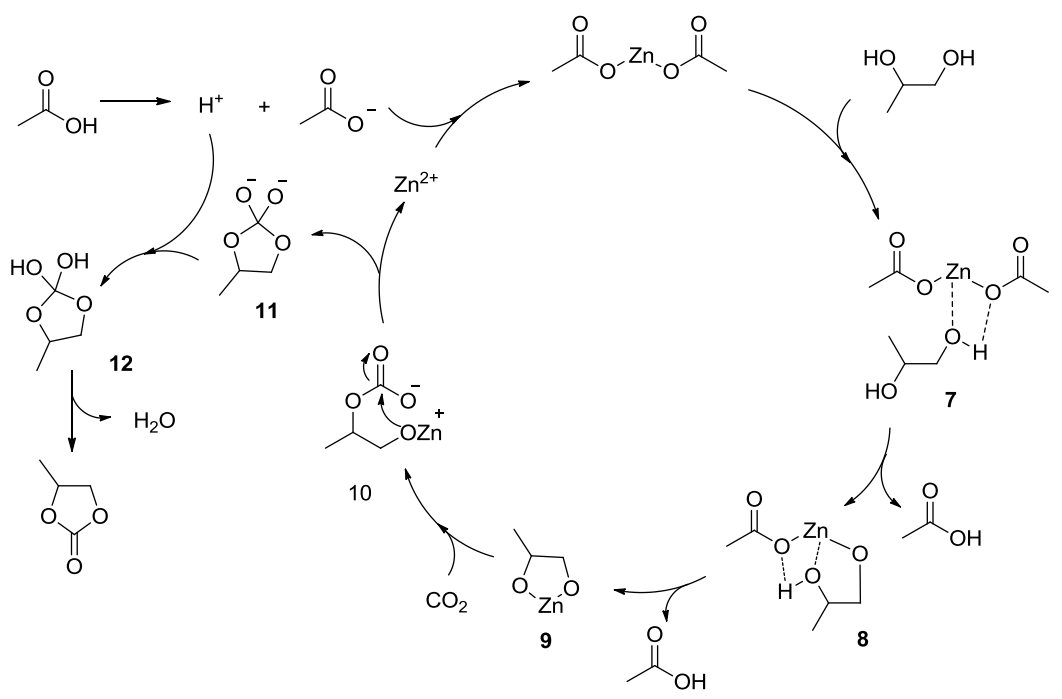

Scheme 6. $\mathrm{Zn}(\mathrm{OAc})_{2}$-catalyzed mechanism for $\mathrm{PC}$ synthesis. 
Different metallic acetates (e.g. $\left.\mathrm{Zn}(\mathrm{OAc})_{2}\right)$ are used as catalysts for the synthesis of cyclic carbonates from $\mathrm{CO}_{2}$ and 1,2-diols with $\mathrm{CH}_{3} \mathrm{CN}$ as solvent [31]. Under optimal conditions, the yield of 1,2-propylene carbonate reaches $24.2 \%$ with $38.9 \%$ conversion of 1,2-propylene glycol. A possible mechanism is proposed as below: firstly, anhydrous $\mathrm{Zn}(\mathrm{OAc})_{2}$ interacts with $\mathrm{PG}$ to form the complex 7 . Secondly, 7 eliminates two molecules of acetic acid to form 9. Then, $\mathbf{9}$ can attack at $\mathrm{CO}_{2}$ to afford the intermediate $\mathbf{1 1}$ and releases $\mathrm{Zn}^{2+}$. At last, $\mathbf{1 1}$ combines with $\mathrm{H}^{+}$to form $\mathrm{PC}$ with the regeneration of the catalyst (Scheme 6) [32].

\subsection{Organic/Inorganic Base-catalyzed Carbonate Synthesis}

Alkali carbonates have also been found to be catalysts for PC synthesis from PG and $\mathrm{CO}_{2}$ [33]. A series of alkali carbonates are examined systematically and potassium carbonate shows the highest catalytic activity. On the other hand, benzonitrile can used as an excellent dehydrating reagent in place of $\mathrm{CH}_{3} \mathrm{CN}$ to overcome some drawbacks such as low boiling point, toxicity and high polarity [34].

Apart from inorganic base, organic base can also promote the synthesis of cyclic carbonates from 1,2-diols and $\mathrm{CO}_{2}$ $[35,36] .15 .3 \%$ yield and $100 \%$ selectivity can be attained when 1,5,7-triazabicyclo[4.4.0]dec-5-ene (TBD) is used as a catalyst under the optimal conditions. In addition, 1,8diazabicy-clo[5.4.0] undec-7-ene(DBU) and triethylamine (TEA) have also been active for the carboxylative cyclization of 1,2-diols with $\mathrm{CO}_{2}$.

Through analyzing the optimized structures and energy of different probable routes by density functional theory (DFT) calculation, the dehydration step of the secondary hydroxyl in the PG-activated mechanism is identified as the most possible reaction pathway with the lowest energy barrier of $56.96 \mathrm{kcal} / \mathrm{mol}$. TBD can be considered as a proton bridge activated by the synergistic effect of the $\mathrm{N}$ atoms. The proton transfer activity makes the deprotonated species more susceptible to be attacked by $\mathrm{CO}_{2}$ [37]. The possible mechanism has been proposed as follows: the secondary hydroxyl of PG is captured by TBD, followed by the attack of $\mathrm{CO}_{2}$ at the $\mathrm{O}$ atom of hydroxyl resulting in the formation of the "ion-pair" $\left(\mathrm{TBDH}^{+}\right.$and $\mathrm{RCO}_{3}{ }^{-}$) [38]. Finally, the proton migrates from $\mathrm{TBDH}^{+}$to the other hydroxyl group to form water with the regeneration of TBD. Simultaneously, intramolecular nucleophilic substitution affords $\mathrm{PC}$ as depicted in Scheme 7.

\subsection{Rh-catalyzed Cyclic Carbonate Synthesis}

Transition metal compound e.g. $\mathrm{RhCl}_{3}$ has also been engaged with the aid of $\mathrm{KI}$ to promote the preparation of glycerol carbonate from $\mathrm{CO}_{2}$ and glycerol [39] as shown in Scheme (8). Phosphine ligand such as $\mathrm{PPh}_{3}$ or dppp [1,3-bis (diphenylphosphino) propane] is used to stabilize the rhodium complex and thus enhances the reaction. Moreover, the catalytic efficiency strongly depends on both the amount of $\mathrm{KI}$ and the reaction temperature.

\section{OTHER STRATEGIES FOR CYCLIC CARBONATE SYNTHESIS}

In addition to direct synthesis from $\mathrm{PG}$ and $\mathrm{CO}_{2}$, cyclic carbonate can also be prepared from the derivatives of 1,2diols. Cyclic ketal, such as 1,4-dioxaspiro[4.5]decane which derives from cyclohexanone and glycol is able to reat with $\mathrm{CO}_{2}$ to provide $\mathrm{EC}$ in the presence of $\mathrm{FeCl}_{3}$ without dehydration and nor thermodynamic limitation [40]. Transition metal complexes with functionalized fluorinated di-ketone ligand $\left(\mathrm{CuL}_{2}\right.$ or FeClL) are also introduced as high active catalysts as demonstrated in Scheme 9. The ligand is believed to enhance the solubility of the metal catalyst. In addition, the solvent effect is significant. Toluene and $\mathrm{CH}_{3} \mathrm{CN}$ work well, whereas $\mathrm{CH}_{3} \mathrm{OH}$ drastically prevents EC formation, resulting in producing 1,1-dimethoxycyclohexane as the sole product.

Urea is considered as an equivalent of $\mathrm{CO}_{2}$ because it can be easily synthesized from $\mathrm{CO}_{2}$ and $\mathrm{NH}_{3}$ [41]. In this context, synthesis of cyclic carbonates from urea and 1,2-

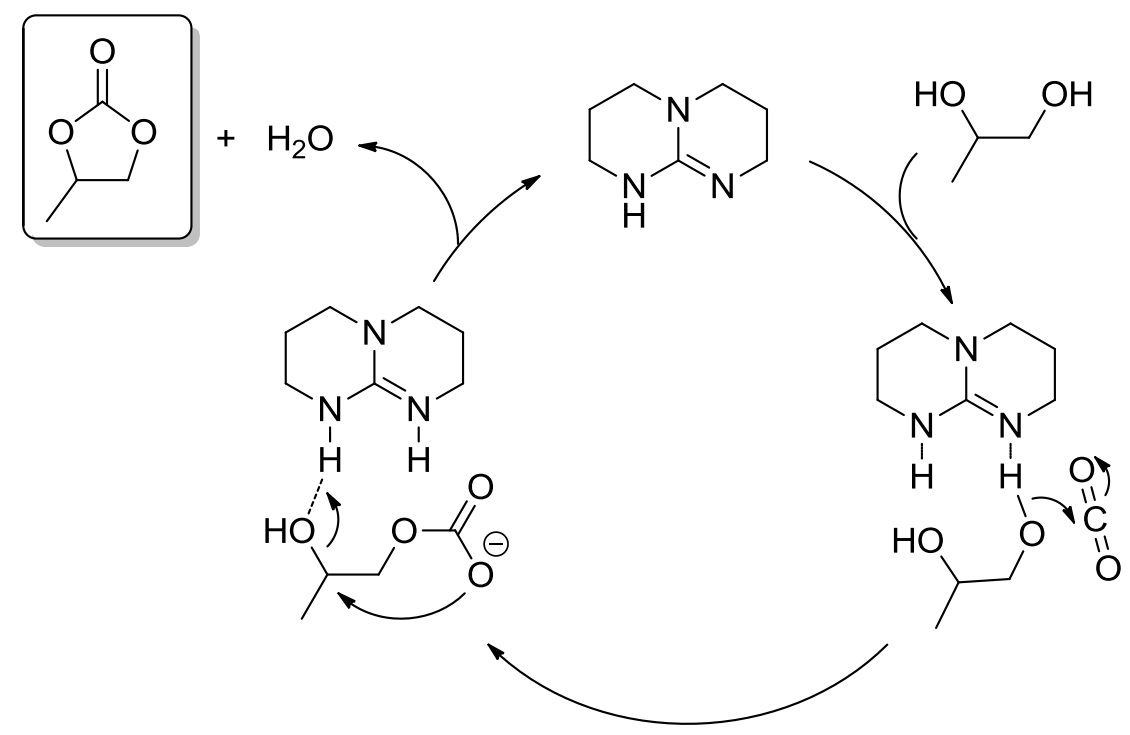

Scheme 7. PG-activated route to TBD-catalyzed PC synthesis. 


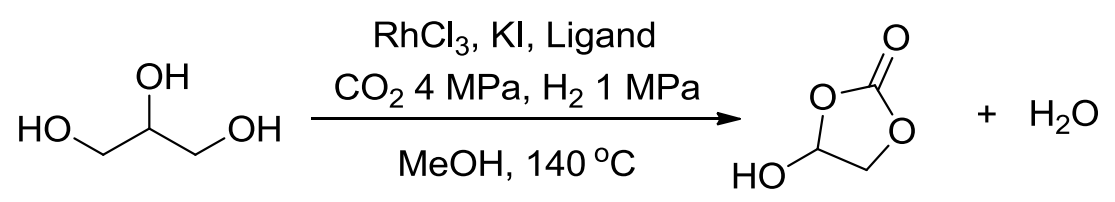

Scheme 8. Glycerol carbonate synthesis catalyzed by $\mathrm{RhCl}_{3}$.

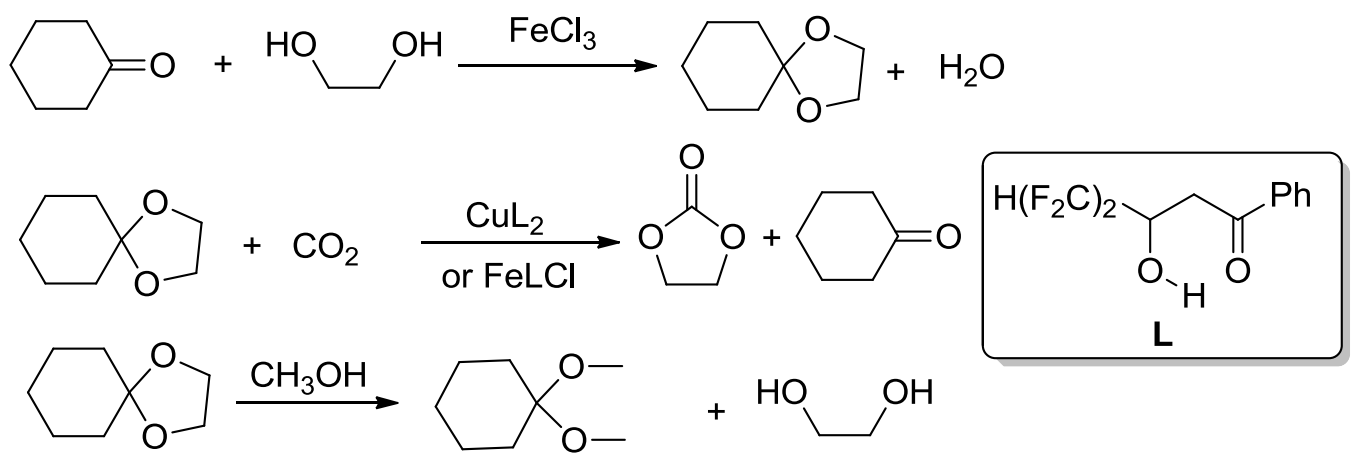

Scheme 9. The synthesis of EC from cyclic ketal and $\mathrm{CO}_{2}$.

diols has many advantages, such as economic benefits, easy handing, low toxicity and so on. Most of all, this route exists no thermodynamic limitation and thus gives high yield of the target products under mild conditions [42]. Catalysts with appropriate acidic and basic properties such as $\mathrm{ZnO}$ can activate urea to form the isocyanate species [42], which then reacts with 1,2-diol leading to affording cyclic carbonate in high yield and selectivity as illuminated in Scheme 10.

On the other hand, transesterification of 1,2-diols with alkyl carbonates under mild conditions also has been widely investigated for the preparation of cyclic carbonates [43-45]. Basic catalysts are found to more active than acidic ones. For example, $100 \%$ yield and selectivity can be achieved when strong base such as $\mathrm{NaOH}, \mathrm{KOH}$ or $\mathrm{K}_{2} \mathrm{CO}_{3}$ is used. Furthermore, the base-promoted mechanism is proposed as below. Glycerol reacts with a base to form glyceroxide anion 13. The $\mathrm{f}$ transesterification of $\mathbf{1 3}$ with DMC generates the intermediate 14 with the regeneration of the base. In the presence of the base, the intramolecular transesterification takes likely place to form glycerol carbonate as illustrated in Scheme 11.

An alternative pathway is also developed to prepare glycerol carbonate from glycerol and $\mathrm{CO}_{2}$ catalyzed by $\mathrm{KI}$, in which propylene oxide is introduced as coupling agent (Scheme 12) [46]. The conversion of glycerol could be as high as $90 \%$ under optimal reaction conditions. Given that compounds with hydroxyl group can act as co-catalysts to promote the cycloaddition of $\mathrm{CO}_{2}$ with epoxides through hydrogen bond formation, we can conjecture that glycerol and PG work not only as the reactants, but also as cocatalysts to promote the key step of the coupling reaction significantly, and make the reaction thermodynamically favorable [47-49].

\section{CONCLUSION}

In this review article, the recent advances in the synthesis of cyclic carbonates from 1,2-diols and $\mathrm{CO}_{2}$, especially direct synthesis from 1,2-diols (EG, PG, glycerol) and $\mathrm{CO}_{2}$ have been intensively summarized as shown in Scheme 13. Metallic oxides, metal carbonates, organic bases, and transition metal complexes are found to be efficient catalysts for this reaction. In addition, the catalytic cycles are discussed on a molecular level.

Despite the fact that only a handful of reported catalysts can get both high selectivity and yield of the carbonate simultaneously, effective synthesis of cyclic carbonates

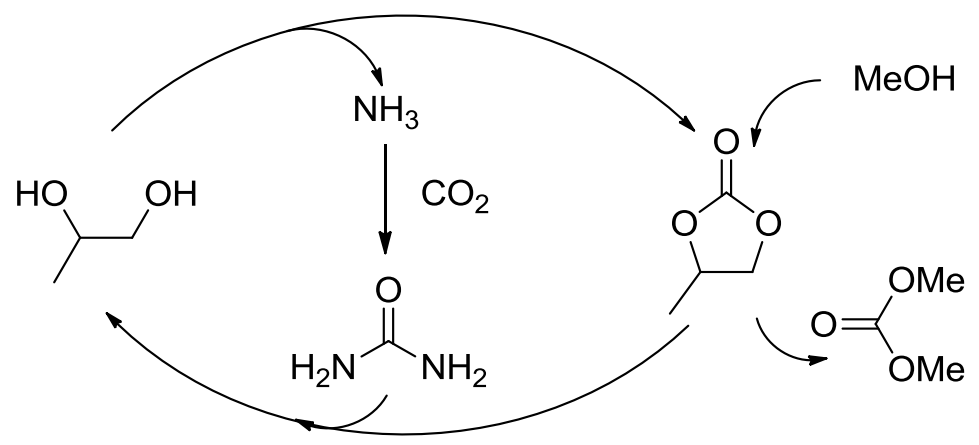

Scheme 10. Synthesis of cyclic carbonates via urea alcoholysis. 

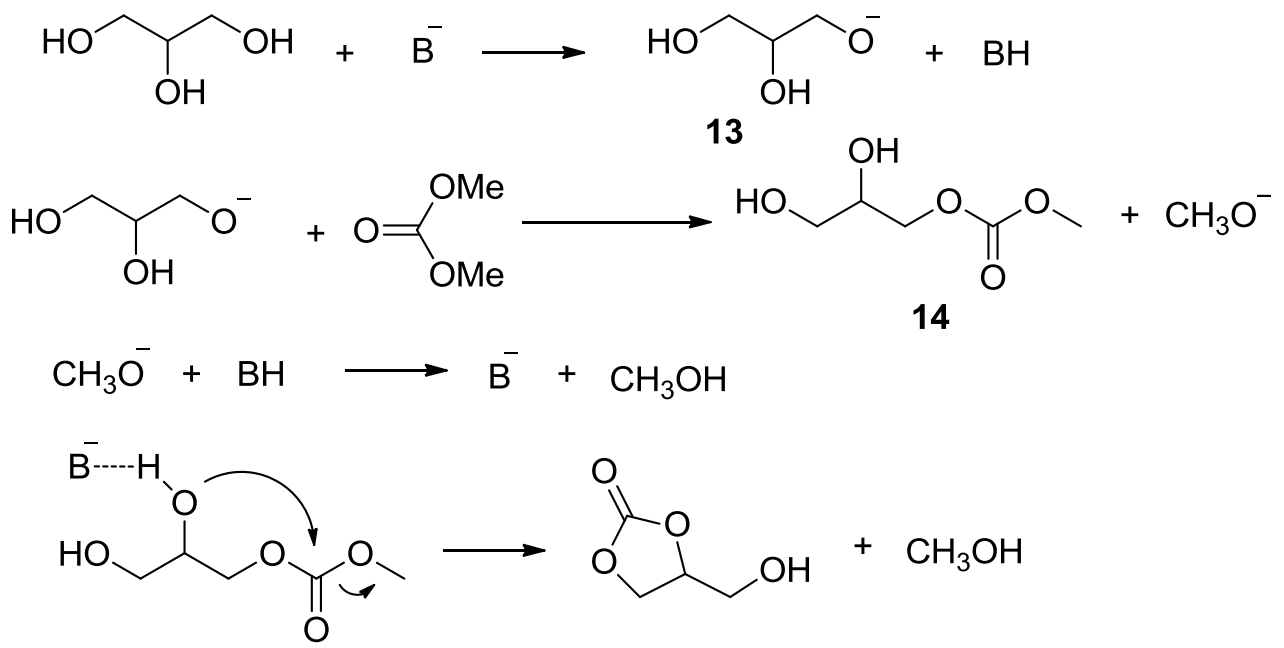

Scheme 11. The base-promoted transesterification of glycerol with DMC.<smiles>CC1COC(=O)O1</smiles>

Scheme 12. The integration process of $\mathrm{CO}_{2}$, glycerol and $\mathrm{PO}$ to produce cyclic carbonate.

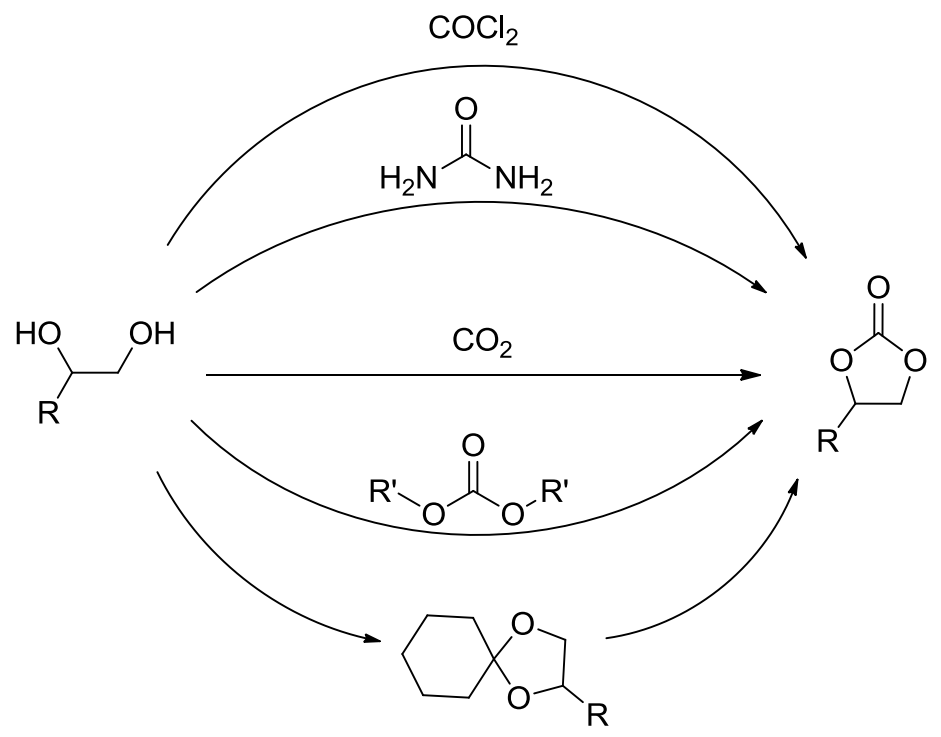

Scheme 13. Approaches to cyclic carbonates from 1,2-diols and $\mathrm{CO}_{2}$

directly from 1,2-diols and $\mathrm{CO}_{2}$ could be a useful methodology for academic research and potential application in industry. We believe this presentation would stimulate us to further develop more greener processes for the production of organic carbonates from $\mathrm{CO}_{2}$.

\section{CONFLICT OF INTEREST}

Declared none.

\section{ACKNOWLEDGEMENTS}

We are grateful to the National Natural Sciences Foundation of China (No. 21172125, 21121002, 21472103),
Specialized Research Fund for the Doctoral Program of Higher Education (20130031110013), MOE Innovation Team (IRT13022) of China for financial support.

\section{REFERENCES}

[1] Bakker, D.; Watson, A. Global change: A piece in the $\mathrm{CO}_{2}$ jigsaw. Nature, 2001, 410(6830), 765-766

[2] Federsel, C.; Jackstell, R.; Beller, M. State-of-the-Art Catalysts for Hydrogenation of Carbon Dioxide. Angew. Chem. Int. Ed., 2010, 49(36), 6254-6257

[3] Keith, D.W. Why capture $\mathrm{CO}_{2}$ from the atmosphere? Science, 2009 325(5948), 1654-1655.

[4] Sakakura, T.; Choi, J-C.; Yasuda, H. Transformation of Carbon Dioxide. Chem. Rev., 2007, 107(6), 2365-2387. 
[5] Cokoja, M.; Bruckmeier, C.; Rieger, B.; Herrmann, W.; Kühn, F.E. Transformation of carbon dioxide with homogeneous transitionmetal catalysts: a molecular solution to a global challenge? Angew. Chem. Int. Ed., 2011, 50(37), 8510-8537.

[6] Yang, Z-Z.; He, L-N.; Gao, J.; Liu, A-H.; Yu, B. Carbon dioxide utilization with $\mathrm{C}-\mathrm{N}$ bond formation: carbon dioxide capture and subsequent conversion. Energy. Environ. Sci., 2012, 5(5), 66026639.

[7] Yoshida, M.; Ihara, M. Novel methodologies for the synthesis of cyclic carbonates. Chem. Eur. J., 2004, 10(12), 2886-2893.

[8] Shaikh, A-AG.; Sivaram, S. Organic Carbonates. Chem, Rev., 1996, 96(3), 951-976.

[9] Ono, Y. Catalysis in the production and reactions of dimethyl carbonate, an environmentally benign building block. Appl. Catal. A.: Gen., 1997, 155(2), 133-166.

[10] Aresta, M.; Quaranta, E. Carbon dioxide: A substitute for phosgene. Chemtech, 1997, 27(3), 32-40.

[11] Kizlink, J.; Pastucha, I. Preparation of dimethyl carbonate from methanol and carbon dioxide in the presence of Sn(IV) and Ti(IV) alkoxides and metal acetates. Collect. Czech Chem. C., 1995, 60(4), 687-692.

[12] Sakakura, T.; Choi J-C, Saito, Y.; Sako, T. Synthesis of dimethyl carbonate from carbon dioxide: catalysis and mechanism. Polyhedron, 2000, 19(5), 573-576.

[13] Choi, J-C.; He, L-N.; Yasuda, H.; Sakakura, T. Selective and high yield synthesis of dimethyl carbonate directly from carbon dioxide and methanol. Green. Chem., 2002, 4(3), 230-234.

[14] Tomishige, K.; Yasuda, H.; Yoshida, Y.; Nurunnabi, M.; Li, B.; Kunimori, K. Novel route to propylene carbonate: selective synthesis from propylene glycol and carbon dioxide. Catal. Lett., 2004, 95(1/2), 45-49.

[15] Tomishige, K.; Yasuda, H.; Yoshida, Y.; Nurunnabi, M.; Li, B.; Kunimori, K. Catalytic performance and properties of ceria based catalysts for cyclic carbonate synthesis from glycol and carbon dioxide. Green. Chem., 2004, 6(4), 206-214.

[16] Sakakura, T.; Saito, Y.; Okano, M.; Choi, J-C.; Sako, T. Selective conversion of carbon dioxide to dimethyl carbonate by molecular catalysis. J. Org. Chem., 1998, 63(20), 7095-7096.

[17] Ballivet-Tkatchenko, D.; Ligabue, R.; Plasseraud, L. Synthesis of dimethyl carbonate in supercritical carbon dioxide. Braz. J. Chem. Eng., 2006, 23(1), 111-116.

[18] Sakakura, T.; Choi, J-C.; Saito, Y.; Masuda, T.; Sako, T.; Oriyama, T. Metal-Catalyzed dimethyl carbonate synthesis from carbon dioxide and acetals. J. Org. Chem., 1999, 64(12), 4506-4508.

[19] Du, Y.; Kong, D-L.; Wang, H-Y.; Cai, F.; Tian, J-S.; Wang, J-Q.; He, L-N. Sn-catalyzed synthesis of propylene carbonate from propylene glycol and $\mathrm{CO}_{2}$ under supercritical conditions. J. Mol. Catal. A.: Chem., 2005, 241(1-2), 233-237.

[20] Shanzer, A.; Libman, J.; Gottlieb, H.; Frolow, F. Synthesis with tin templates. A new family of diastereomeric macrocycles. J. Am. Chem. Soc., 1982, 104(15): 4220-4225.

[21] Aresta, M.; Dibenedetto, A.; Nocito, F.; Pastore, C. A study on the carboxylation of glycerol to glycerol carbonate with carbon dioxide: The role of the catalyst, solvent and reaction conditions. $J$. Mol. Catal. A.: Chem., 2006, 257(1-2), 149-153.

[22] Ballivet-Tkatchenko, D.; Burgat, R.; Chambrey, S.; Plasseraud, L.; Richard, P. Reactivity of ditert-butyldimethoxystannane with carbon dioxide and methanol: X-ray structure of the resulting complex. J. Organomet. Chem., 2006, 691(8), 1498-1504.

[23] George, J.; Patel, Y.; Pillai, S.M.; Munshi, P. Methanol assisted selective formation of 1,2-glycerol carbonate from glycerol and carbon dioxide using $\mathrm{nBu}_{2} \mathrm{SnO}$ as a catalyst. J. Mol. Catal. A.: Chem., 2009, 304(1-2), 1-7.

[24] Du, Y.; He, L-N.; Kong, D-L. Magnesium-catalyzed synthesis of organic carbonate from 1,2-diol/alcohol and carbon dioxide. Catal. Commun., 2008, 9(8), 1754-1758.

[25] Huang, S.; Liu, S.; Li, J.; Zhao, N.; Wei, W.; Sun, Y. Modified zinc oxide for the direct synthesis of propylene carbonate from propylene glycol and carbon dioxide. Catal. Lett., 2007, 118(3/4), 290-294.

[26] Rhodes, C.N.; Brown, D.R. Surface properties and porosities of silica and acid-treated montmorillonite catalyst supports: influence on activities of supported $\mathrm{ZnCl}_{2}$ alkylation catalysts. J. Chem. Soc., Faraday Trans., 1993, 89(9), 1387-1391.

[27] Huang, S.; Liu, S.; Li, J.; Zhao, N.; Wei, W.; Sun Y. Effective synthesis of propylene carbonate from propylene glycol and carbon dioxide by alkali carbonates. Catal. Lett., 2006, 112(3-4), 187-191.

[28] Li, H.; Gao, D.; Gao, P.; Wang, F.; Zhao, N.; Xiao, F.; Wei, W.; Sun, Y. The synthesis of glycerol carbonate from glycerol and $\mathrm{CO}_{2}$ over $\mathrm{La}_{2} \mathrm{O}_{2} \mathrm{CO}_{3}-\mathrm{ZnO}$ catalysts. Catal. Sci. Technol., 2013, 3(10), 2801-2809.

[29] Tichit, D.; Das, N.; Coq, B.; Durand, R. Preparation of Zrcontaining layered double hydroxides and characterization of the acido-basic properties of their mixed oxides. Chem. Mater, 2002, 14(4), 1530-1538.

[30] Wu, G.; Wang, X.; Wei, W.; Sun Y. Fluorine-modified Mg-Al mixed oxides: A solid base with variable basic sites and tunable basicity. Appl. Catal. A.: Gen., 2010, 377(1-2), 107-113.

[31] Huang, S-y.; Liu, S-g.; Li, J-p.; Zhao, N.; Wei, W.; Sun, Y-h. Synthesis of cyclic carbonate from carbon dioxide and diols over metal acetates. J. Fuel. Chem. Technol., 2007, 35(6), 701-705.

[32] Zhao, X.; Sun, N.; Wang, S.; Li, F.; Wang, Y. Synthesis of propylene carbonate from carbon dioxide and 1,2-Propylene glycol over zinc acetate catalyst. Ind. Eng. Chem. Res., 2008, 47(5), 13651369.

[33] Hong, C.; Xinqiang, Z.; Yanji, W. Synthesis of propylene carbonate from carbon dioxide and 1, 2-propylene glycol over potassium carbonate catalyst. Petrochem. Tech., 2005, 34(11), 1037.

[34] Da Silva, E.; Dayoub, W.; Mignani, G.; Raoul, Y.; Lemaire, M. Propylene carbonate synthesis from propylene glycol, carbon dioxide and benzonitrile by alkali carbonate catalysts. Catal. Commun., 2012, 29(0), 58-62.

[35] Huang, S.; Ma, J.; Li, J.; Zhao, N.; Wei, W.; Sun, Y. Efficient propylene carbonate synthesis from propylene glycol and carbon dioxide via organic bases. Catal. Commun., 2008, 9(2), 276-280.

[36] Ma, J.; Zhang, X.; Zhao, N.; Al-Arifi, A.S.N.; Aouak, T.; AlOthman, Z.A.; Xiao, F.; Wei, W.; Sun, Y. Theoretical study of TBDcatalyzed carboxylation of propylene glycol with $\mathrm{CO}_{2}$. J. Mol. Catal. A.: Chem., 2010, 315(1), 76-81.

[37] Abla, M.; Choi, J-C.; Sakakura, T. Halogen-free process for the conversion of carbon dioxide to urethanes by homogeneous catalysis. Chem. Commun., 2001, (21), 2238-2239.

[38] Brzezinski, B.; Schroeder, G.; Rybachenko, V.; Kozhevina, L.; Kovalenko, V. Study of 1,5,7-triazabicyclo[4,4,0]dec-5-ene protonation by vibrational spectroscopic methods. J. Mol. Struct., 2000, 516(2), 123-130.

[39] Ezhova, N.; Korosteleva, I.; Kolesnichenko, N.; Kuz'min, A. Khadzhiev, S.; Vasil'eva, M.; Voronina, Z. Glycerol carboxylation to glycerol carbonate in the presence of rhodium complexes with phosphine ligands. Petrol. Chem., 2012, 52(2), 91-96.

[40] Aresta, M.; Dibenedetto, A.; Dileo, C.; Tommasi, I.; Amodio, E. The first synthesis of a cyclic carbonate from a ketal in $\mathrm{SC}^{-\mathrm{CO}_{2} .} J$. Supercrit. Fluid, 2003, 25(2), 177-182.

[41] Ball, P.; Füllmann, H.; Heitz, W. Carbonates and polycarbonates from urea and alcohol. Angew. Chem. Int. Ed., 1980, 19(9), 718720.

[42] Li, Q.; Zhang, W.; Zhao, N.; Wei, W.; Sun, Y. Synthesis of cyclic carbonates from urea and diols over metal oxides. Catal. Today, 2006, 115(1-4), 111-116.

[43] Li, J.; Wang, T. Coupling reaction and azeotropic distillation for the synthesis of glycerol carbonate from glycerol and dimethyl carbonate. Chem. Eng. Process, 2010, 49(5), 530-535.

[44] Ochoa-Gómez, J.R., Gómez-Jiménez-Aberasturi, O., MaestroMadurga, B., Pesquera-Rodríguez, A., Ramírez-López, C., Lorenzo-Ibarreta, L., Torrecilla-Soria, J., Villarán-Velasco, M.C. Synthesis of glycerol carbonate from glycerol and dimethyl carbonate by transesterification: Catalyst screening and reaction optimization. Appl. Catal. A.: Gen., 2009, 366(2), 315-324.

[45] Simanjuntak, F.S.H.; Kim, T.K.; Lee, S.D.; Ahn, B.S.; Kim, H.S.; Lee, H. CaO-catalyzed synthesis of glycerol carbonate from glycerol and dimethyl carbonate: Isolation and characterization of an active Ca species. Appl. Catal. A.: Gen., 2011, 401(1), 220-225.

[46] Ma, J.; Song, J.; Liu, H.; Liu, J.; Zhang, Z.; Jiang, T.; Fan, H.; Han, B. One-pot conversion of $\mathrm{CO}_{2}$ and glycerol to value-added products using propylene oxide as the coupling agent. Green Chem., 2012, 14(6), 1743-1748.

[47] Zhu, A.; Jiang, T.; Han, B.; Zhang, J.; Xie, Y.; Ma.; X. Supported choline chloride/urea as a heterogeneous catalyst for chemical fixation of carbon dioxide to cyclic carbonates. Green Chem., 2007, 9(2), 169-172.

[48] Takahashi, T.; Watahiki, T.; Kitazume, S.; Yasuda, H.; Sakakura T. Synergistic hybrid catalyst for cyclic carbonate synthesis: 
Remarkable acceleration caused by immobilization of homogeneous catalyst on silica. Chem. Commun., 2006, (15), 16641666.
[49] Huang, J-W.; Shi, M. Chemical Fixation of Carbon Dioxide by $\mathrm{NaI} / \mathrm{PPh}_{3} / \mathrm{PhOH}$. J. Org. Chem., 2003, 68(17), 6705-6709.

Received: March 12, 2014

Revised: August 20, 2014

Accepted: August 27, 2014

(c) Guo et al; Licensee Bentham Open.

This is an open access article licensed under the terms of the Creative Commons Attribution Non-Commercial License (http://creativecommons.org/licenses/ by-nc/3.0/) which permits unrestricted, non-commercial use, distribution and reproduction in any medium, provided the work is properly cited. 